\title{
O controle das emoções na escrita acadêmica e seu impacto na relação do indivíduo com o trabalho intelectual $^{1}$
}

\author{
Camila Ribeiro de Almeida Rezende* \\ Ana Luisa Fayet Sallas**
}

\section{Resumo}

0 trabalho intelectual é fomentado por meio da escrita acadêmica, que é tanto permeada por questões subjetivas - distintas e singulares para cada indivíduo - quanto por questões socialmente compartilhadas - imaginários coletivos de significação e interpretações do campo acadêmico que a constrói. No atual contexto brasileiro, o aumento da cobrança por produtividade tem intensificado o status da escrita como moeda de troca e afetado a relação entre trabalho e emoções na produção intelectual. Em resposta a esse panorama social, algumas universidades têm buscado saídas para lidar com a problemática da produtividade acadêmica. Assim, este artigo busca compartilhar um estudo de caso feito na Universidade Federal do Paraná (UFPR), que, em 2016, inaugurou o Centro de Assessoria de Publicação Acadêmica (CAPA), o primeiro writing center brasileiro. Por meio da observação participante como assessora de escrita acadêmica de diferentes estudantes de pós-graduação nesse centro e de respostas coletadas por meio de questionários aplicados nas assessorias, buscamos refletir sobre o controle das emoções na escrita acadêmica e seu impacto na relação do indivíduo com o trabalho intelectual. 0 embasamento teórico é apoiado nas intersecções entre a sociologia das emoções, do corpo e da arte, o que permite compreender como a regulação da escrita no meio acadêmico opera tanto no âmbito estético/gramatical quanto no controle da emotividade do indivíduo no texto, sedimentando e perpetuando as dicotomias corpo/mente, arte/ciência, emoção/razão, e influenciando, assim, as construções epistemológicas.

\footnotetext{
${ }^{1}$ O presente trabalho foi realizado com apoio da Coordenação de Aperfeiçoamento de Pessoal de Nível Superior-Brasil (CAPES) - Código de Financiamento 001.

*Camila Ribeiro de Almeida Rezende é doutoranda no Programa de Pós-graduação em Sociologia da Universidade Federal do Paraná (UFPR); Mestra em Artes, Cultura e Linguagens pela Universidade Federal de Juiz de Fora (UFJF); Assessora de escrita acadêmica e Coordenadora de atividades formativas no Centro de Assessoria de Publicação Acadêmica (CAPA) da Universidade Federal do Paraná (UFPR). E-mail: camilararezende@gmail.com.

** Ana Luisa Fayet Sallas é Professora Titular do Programa de Pós-graduação em Sociologia da Universidade Federal do Paraná (UFPR). Realizou pós-doutorado em Sociologia no Centro de Estudos Sociológicos do Colégio do México (2012), Doutora em História pela Universidade Federal do Paraná (1998) e Mestra em Antropologia Social pela Universidade de Brasília (1987).E-mail: analuisa@ufpr.br.
} 


\title{
Palavras-chave
}

Escrita acadêmica. Sociologia das Emoções. Trabalho intelectual.

\begin{abstract}
Intellectual work is often fostered through academic writing, which is pervaded by subjective questions - distinct and unique to each individual - as well as by socially shared questions - collective imaginaries of meaning and interpretations of the academic field that builds it. The currrent increase in demand for productivity among Brazilian scholars has intensified the status of writing as a currency and affected the relationship between work and emotions in intellectual production. In response to this social outlook, some universities have been seeking ways of dealing with the issue of academic productivity. Therefore, this article aims to share a case study performed at the Federal University of Paraná (UFPR), which, in 2016, launched the Academic Publishing Advisory Center (CAPA), the first writing center in Brazil. Through participant observation as an academic writing tutor for different postgraduate students in the center and answers collected through questionnaires applied post tutoring, we strive to reflect on the control of emotions in academic writing and their impact on one's relation with the intellectual creation. The theoretical basis is supported by intersections among sociology of emotions, body and art, which allows us to understand how the regulation of writing in the academic environment operates both in the aesthetic/grammatical scope as well as in the control of emotions by the individual in the text, consolidating and perpetuating the body/mind, art/science and emotion/reason dichotomies, thus influencing epistemological constructions.
\end{abstract}

\section{Keywords}

Academic writing. Sociology of Emotions. Intellectual labor.

\section{Introdução}

O que é escrever? O significado que qualquer dicionário atribui a esse ato, de modo geral, é expressar-se por meio da escrita. Sendo a escrita, então, um meio de expressão, ela está sujeita a uma infinidade de possibilidades, tanto de sentido quanto de forma. Entre essas possibilidades existe um gênero denominado escrita acadêmica, o qual é exercido e regulado pelo campo acadêmico. Sua composição e prática requerem conhecimento não só da língua, mas também das regras do campo, de seu funcionamento e das dinâmicas que o permeiam. Por isso, o significado de expressão nesse 
contexto específico está atrelado a uma regulação.

Segundo o sociólogo Pierre Bourdieu (2008b), a escrita no campo acadêmico pode ser entendida como uma "estrutura estruturante" do meio e possui, portanto, grande poder simbólico, que é convertido em "capital" nas universidades. É por meio da escrita que se avaliam a competência e a qualidade de um pesquisador. Um exemplo disso é o Índice $h$, que contabiliza o número de publicações e citações no meio acadêmico por meio de uma relação quantidade/qualidade, em que a produtividade se torna a norma. ${ }^{2}$ Com base nesse caráter produtivista que a escrita assume, estruturam-se relações de poder, de financiamento e de incentivo às pesquisas nas universidades brasileiras. Assim, ela passa a ser guiada dentro desse campo mais por uma lógica econômica que por uma lógica expressiva. Isso não significa, porém, que a expressividade não exista. Ao que parece, o processo que se instaura é o de uma regulação, um controle excessivo das emoções nessa escrita, que tem por intuito validar o gênero acadêmico como uma prática racional, neutra e objetiva, logo, científica. O que decorre disso é a intensificação de uma oposição entre o gênero acadêmico e o gênero artístico/literário, pois a prática da escrita na arte é vista em antagonismo à escrita científica: ela é emotiva, livre, subjetiva, metafórica e alusiva, logo, expressiva. ${ }^{3}$

Outro fator que intensifica esse imaginário de oposição é a mudança do contexto acadêmico brasileiro. Os novos critérios de pontuação da Coordenação de Aperfeiçoamento de Pessoal de Nível Superior (CAPES) para avaliar os programas de pós-graduação vêm transformando não somente a produção textual nesse meio, mas as relações sociais e a própria relação do indivíduo com o texto. Um exemplo desse panorama pode ser constatado na pesquisa de Ron Martinez (2016), realizada na Universidade Federal do Paraná (UFPR), que aponta que cerca de 70\% dos programas

\footnotetext{
2 “Em 2005 Jorge Hirsch, físico da Universidade da Califórnia em San Diego, propôs o índice h, popularizando a contagem de citações de pesquisadores individuais. O interesse pelo fator de impacto de revistas cresceu de forma constante a partir de 1995. Mais recentemente, ganham impulso métricas relacionadas ao uso social e conversações online - como o F1000 Prime, criado em 2002; o Mendeley, em 2008; e o Altmetric.com, em 2011". (HICKS, 2015, p. 2).

${ }^{3}$ Entretanto, esse antagonismo nem sempre existiu, visto que arte e ciência caminhavam juntas no passado - a exemplo da Antiguidade ao Renascimento, tendo Leonardo da Vinci como o principal expoente. Para mais informações sobre essa oposição, indicamos a tese de Sônia Régis (1996), Literatura como ciência. Um exemplo da análise que ela faz: “No entanto, arte e ciência aparentemente se mostram como duas representações irreconciliáveis no campo do saber humano. Na acepção mais corrente, a meta da ciência parece ser a de ordenar as experiências em sistemas ditos racionais, a da literatura, transformá-las em razões poéticas." (RÉGIS, 1996, p. 5).
} 
de pós-graduação exigem como condição de receber o título de doutor a publicação de pelo menos um artigo em revista de, no mínimo, conceito Qualis B1. O que resulta disso é um aumento de uma lógica produtivista ${ }^{4}$, que faz com que a relação do indivíduo com o texto busque suprir, de maneira emergencial, uma ordem econômica e burocrática para a aquisição do título. Tal relação dificulta a associação da escrita acadêmica como forma de expressão pelo indivíduo, interferindo e disputando espaço de dedicação com os trabalhos acadêmicos que demandam tempo de feitura maior, como dissertações e teses.

Esse aumento de cobrança por publicações nos programas de pósgraduação afeta significativamente a relação emocional de estudantes e professores com a escrita. Entretanto, essa relação emocional não está sendo debatida com a mesma intensidade com que se preconizam as cobranças. Ademais, ela é recorrentemente associada às questões individuais - psicológicas - dos sujeitos, e não às questões de ordem coletiva sociológicas (BECKER, 2015). E, como aponta Barbalet (1998, p.119), a emoção tem uma "base ou fundamento em relações sociais bem como na realidade da experiência individual". Dessa forma, a emoção não pode ser avaliada "simplesmente como um aspecto ou atributo isolados do corpo ou da psicologia de uma pessoa." (BARBALET, 1998, p. 119).

As saídas mais frequentes para lidar com tais questões no contexto acadêmico têm sido o silenciamento e o apagamento dos aspectos emocionais que permeiam a produção escrita. Quanto mais o pesquisador mantém sua vida pessoal e emocional afastada da escrita, mais ele demonstra profissionalismo e competência e, consequentemente, capacidade produtiva. ${ }^{5}$ Quanto mais a escrita é vista como um produto - desligada das subjetividades e dos contextos precários de socialização que as criam -, mais ela incorpora um caráter produtivista e intensifica seu poder simbólico:

\footnotetext{
${ }^{4}$ Ao discutir produtivismo acadêmico neste artigo, pretendemos deixar clara a importância de se problematizar as métricas utilizadas na ciência. A intenção está longe de se pautar em críticas rasas e sem embasamento teórico. Muitas pesquisas já apontam as desigualdades presentes nesse sistema de métricas, desigualdades que envolvem questões econômicas, de nacionalidades, gênero, classe e raça. Como aponta o The Leiden Manifesto for Research Metrics (2015, p. 1), “corremos o risco de prejudicar o sistema da ciência com as próprias ferramentas projetadas para melhorá-lo, uma vez que a avaliação é cada vez mais realizada por instituições sem o devido conhecimento sobre as boas práticas e sobre a interpretação adequada de indicadores."

${ }^{5}$ Caberia para esta discussão uma reflexão sobre Weber e o racionalismo desejado para o homem moderno, e Marx para o fetiche da mercadoria. Outro autor que vem discutindo o tema do produtivismo acadêmico é Thomas Massao Fairchild, em especial no artigo publicado em 2017 sob o título Da interpretação à apreciação: a autoria acadêmica no contexto do novo produtivismo.
} 
a aura de "mistério" que permeia seu processo de criação, que a faz ser concebida como talento ou dom. Assim, tendo por base tal problemática, o que se destaca não é somente a pressão crescente por publicação, mas a falta de discussão e de auxílio diante dessa demanda.

Algumas universidades têm procurado saídas para lidar com a prática da escrita no contexto acadêmico. É o caso da Universidade Federal do Paraná (UFPR), que, em 2016, inaugurou o Centro de Assessoria de Publicação Acadêmica (CAPA). Pensando em auxiliar os estudantes com a pressão por publicação, o CAPA surgiu como um espaço de diálogo sobre a escrita, pois "a produção de textos acadêmicos melhora quando o processo é um ato social que envolve diálogo com outras pessoas, especialmente colegas, e em ambientes interdisciplinares." (CAPA, 2018). Esse diálogo é focado no processo, e não na escrita como produto. Visando apoiar a formação de autores acadêmicos, o CAPA surgiu como o primeiro writing center ${ }^{6}$ brasileiro:

Os writing centers começaram a surgir nos Estados Unidos há mais de meio século, mas no Brasil ainda são desconhecidos. A ideia principal por trás deles é muito simples: os alunos - e até os professores - podem ajudar uns aos outros. Existe uma pressão grande para escrever textos acadêmicos de boa qualidade, e não se pode depender exclusivamente do professor para formar bons escritores. Os writing centers nos Estados Unidos treinam alunos de graduação e pós-graduação que já são bons escritores a ensinarem seus colegas a também desenvolverem essa habilidade. Portanto, o CAPA se inspirou em alguns dos melhores writing centers dos Estados Unidos, como o da University of Maryland, o da University of Columbia e o da University of Notre Dame, e de outros países do mundo, como o da University of Adelaide (Austrália) e o da University of Plymouth (Reino Unido). (CAPA, 2018).

O CAPA, portanto, configura-se como um novo ambiente de interação na universidade. Segundo Becker (2007), a prática de compartilhar textos com outras pessoas, sem estar na versão final, para serem lidos e criticados não é comum na pós-graduação e tem um sentido diferente do tradicional que é perpetuado nesse meio. Visto que o CAPA é a primeira experiência

\footnotetext{
${ }^{6}$ A influência dos EUA na lógica produtivista e o próprio fato de serem os pioneiros na criação de writing centers demonstram a preocupação com a escrita como meio de produção/ expressão.
} 
de centro de escrita acadêmica do Brasil, a investigação desse novo contexto se torna importante para compreendermos as mudanças e os efeitos no campo social e na construção do trabalho intelectual - este compreendido, sobretudo, ainda como uma prática individual.

Se a escrita acadêmica é permeada por um "mistério", um "dogma", praticada solitariamente, raramente compartilhada e apenas discutida quando concluída, qual seria o efeito na mudança dessa lógica? Se o processo for entendido e praticado como um ato coletivo, envolvendo diálogo com outros indivíduos, e nesse diálogo for dada uma abertura para expor as emoções presentes, qual o efeito disso no processo da escrita e no campo acadêmico?

Desse modo, neste artigo buscamos refletir o controle das emoções na escrita acadêmica e seu impacto na relação do indivíduo com o trabalho intelectual. Para tanto, essa reflexão parte de um estudo de caso com observação participante no CAPA. Em termos organizacionais, o artigo encontra-se dividido em três seções. Na primeira, CAPA: um outro contexto de socialização do trabalho da escrita, apresentamos o contexto de criação do CAPA e sua forma de atuação na produção do conhecimento e da escrita. $\mathrm{Na}$ segunda, Algumas possibilidades de análise do imaginário na escrita acadêmica, discutimos o papel das emoções na escrita e os imaginários dicotômicos entre arte/ciência, emoção/razão, corpo/mente. Por fim, nas Considerações finais, buscamos contribuir com uma abertura reflexiva sobre as questões aqui investigadas.

\section{CAPA: um outro contexto de socialização do trabalho da escrita}

O Centro de Assessoria de Publicação Acadêmica (CAPA) surgiu em 2016 e foi idealizado pelo professor Dr. Ron Martinez, do Departamento de Letras Estrangeiras Modernas e do Programa de Pós-Graduação de Letras da Universidade Federal do Paraná. Entre as diferentes atividades promovidas pelo CAPA (tradução e revisão de textos acadêmicos, workshops, palestras, dias de produção ${ }^{7}$ ), as assessorias têm destaque e importância maior nesse

\footnotetext{
${ }^{7}$ Os dias de produção visam fomentar uma conscientização da escrita acadêmica como um trabalho, praticado paulatinamente por meio de horas de dedicação. Assim, o foco dessa atividade é passar uma parte do dia (geralmente sábado, das nove da manhã às três da tarde) compartilhando um mesmo ambiente para trabalhar a escrita de textos acadêmicos. São ofertadas entre 20 e 25 vagas para que escritores acadêmicos utilizem uma sala em conjunto, onde cada qual com seu material e equipamento desenvolvam suas escritas particulares, contando com a ajuda de assessores do CAPA. Se a escrita travar, se surgir alguma dúvida, os
} 
centro. Elas são, portanto, a prática específica de análise neste artigo. As assessorias são fundamentadas no diálogo sobre a escrita e podem ser agendadas no site do CAPA por qualquer membro da comunidade acadêmica (alunos, professores, técnicos etc.) e também da comunidade externa. Elas têm duração de 50 minutos e se configuram como um espaço de livre diálogo sobre as dificuldades ou dúvidas que o(a) assessorado(a) esteja enfrentando com a escrita. Nesse espaço, ele(a) pode levar seu texto em qualquer estágio de construção ou até mesmo ir somente com a ideia ou a intenção.

A prática de assessoria é um novo tipo de relação no campo acadêmico brasileiro, pois possibilita a quebra de algumas hierarquias existentes. Quando o indivíduo busca esse auxílio, ele é ouvido pelo(a) assessor(a), uma pessoa que não está estritamente inserida em sua área de estudo na universidade e que, portanto, possui uma ligação bem distinta da que um(a) colega de turma, um(a) professor(a) ou orientador(a) apresentam que, para Kemper (2006), seriam relações baseadas em um espaço definido pelas dimensões de status de poder. Desse modo, a assessoria tende a propiciar uma liberdade maior na fala do(a) assessorado(a), uma vez que o(a) assessor(a) é um indivíduo capacitado que está ali para auxiliar no processo criativo da escrita, e não para julgar o conteúdo, os conceitos ou a fala do(a) assessorado(a).

Nas observações de campo feitas até o momento, observou-se que as principais imagens construídas acerca do(a) assessor(a) são a de uma pessoa que ajudará na forma, na estética da escrita e/ou no processo criativo. Além disso, em vários casos, o(a) assessor(a) foi visto como alguém com o(a) qual o(a) assessorado(a) sente-se seguro(a) e confiante para compartilhar a "desordem" do seu processo, para expressar o que tem mantido sob sigilo, expressar seu desconforto por "não saber de que modo escrever", "de que modo pesquisar", "como articular as ideias no texto". Logo, é possível identificar nesse contexto de interação um processo social que permite a expressão e o compartilhamento de emoções como insegurança, baixa confiança, vergonha, medo, entre outras, que podem interferir de modo negativo no ato da escrita e que, em alguns casos, impedem até mesmo a sua prática.

assessores se tornam presentes para auxiliar na continuação do processo de escrita. A coerção social de ver outros indivíduos também trabalhando e produzindo suas escritas nesse espaço faz com que haja uma persistência de continuação e retrabalho da escrita durante as horas de atividades do dia de produção. 
Mesmo que ainda exista nessa dinâmica da assessoria uma relação hierárquica - o(a) assessor(a) - que conhece o processo da escrita - versus o(a) assessorado(a) - que possuiu o conhecimento científico a ser trabalhado na escrita - a maioria das dinâmicas apresentam trocas igualitárias, sem perda de status de ambos os envolvidos (KEMPER, 2006), o que possivelmente proporciona ao(à) assessorado(a) uma interação em que ele(ela) se sente habilitado(a) a dizer muitas coisas que não diria para colegas de curso e professores, orientadores - com os quais cria um vínculo de autoridade e de crença de julgamento. Assim, observamos que a relação que se estabelece nessas interações é de confiança, uma vez que o(a) assessor(a) reconhece as dificuldades do(a) assessorado(a) e apresenta uma projeção de resoluções para os problemas que ele(a) enfrenta com o processo da escrita. Como aponta Barbalet, o objeto central presente na confiança é o plano temporal, o futuro; e, segundo ele, a confiança "funciona no sentido de promover a ação social; surge em (ou é causada por) relações de aceitação e reconhecimento". (BARBALET, 1998, p. 132).

Percebemos que o que ocorre nesse processo de diálogo sobre a escrita é uma outra dinâmica de construção do conhecimento. Como a área de formação do(a) assessor(a) e do(a) assessorado(a) nem sempre é a mesma, a fala do(a) assessorado(a) - já condicionada pelo seu meio acadêmico - passa por um processo de modificação/simplificação para poder se fazer compreendida pelo interlocutor, que é leigo no assunto. Portanto, o ambiente interdisciplinar é capaz de fomentar uma interação distinta daquela exercida no interior dos grupos, das disciplinas e das orientações, pois esse Outro que escuta é aquele que não domina o conteúdo. Nesse movimento de explicar algo que não é "óbvio" para o(a) assessor(a), o(a) assessorado(a) reformula um conteúdo já sedimentado pelo discurso recorrente de sua área e descobre outras possibilidades de entendimento, de exposição de ideias. A escrita, então, abre-se a outras oportunidades, das quais muitas fogem do padrão repetitivo que a hierarquia do campo do indivíduo o induz. Em alguns casos, é nítido que, ao trocar mentalmente o "leitor" do texto (que geralmente é o(a) orientador(a) ou uma banca de avaliação) pelo(a) próprio(a) assessor(a) de escrita acadêmica, o(a) assessorado(a) vislumbra novas possibilidades de construção do próprio conhecimento, permitindo-se uma relação mais afável com a escrita.

Além disso, é interessante destacar o duplo movimento que a assessoria possibilita: da mesma forma que o(a) assessorado(a) se vê obrigado(a) a mudar sua lógica de fala, o(a) assessor(a) também passa pelo mesmo 
processo, visto que ele(a) não pode usar a linguagem condicionada de seu meio, repleta de termos técnicos e teóricos, para explicar ao interlocutor (leigo) o funcionamento do processo de escrita. Consequentemente, o(a) assessor(a) modifica também seu próprio conhecimento acerca da escrita, o que interfere diretamente em sua própria prática textual, pois, à medida que entra em contato com o processo de escrita do outro, aprende novas possibilidades e lógicas e passa a refletir sobre sua própria escrita, pois é com base nela que entende e dialoga sobre o ato de escrever.

Nas observações de campo realizadas por meio de minhas experiências ${ }^{8}$ como assessora de escrita acadêmica no CAPA, o que tenho notado frequentemente é o foco dado pelos(as) assessorados(as) às questões emocionais que permeiam o texto, ao invés das questões técnicas e relativas às regras do gênero e/ou da língua.

Desse modo, antes de iniciar a assessoria, o(a) assessorado(a) preenche um questionário explicitando sua dificuldade com a escrita. Nesse preenchimento, ele(a) relata questões referentes a itens mais técnicos, como dificuldade com a estrutura textual, problemas com coesão e coerência, com ligação entre parágrafos, normas técnicas etc. Entretanto, ao longo do processo de assessoria, esse indivíduo descreve suas emoções acerca da escrita, as relações que mantém com o orientador, com professores e colegas, o bloqueio em escrever, o imaginário do que seria uma "escrita exemplar". O que tenho percebido é que, ao final das assessorias, após o preenchimento de um segundo questionário - que tem por intuito avaliar a experiência desse indivíduo com a assessoria solicitando um feedback -, na maioria (esmagadora) dos casos a resposta é sempre carregada de uma escrita emotiva, diferente da escrita inicial técnica. "Achei excelente a assessoria, foi maravilhosa!!!", “Essa ideia é incrível, tem que ser disseminada", "Muito obrigada, estou me sentindo muito mais confiante!" e "Foi aliviante!" são apenas alguns dos exemplos de feedback recebidos.

Não nos aprofundamos neste artigo na descrição dessas assessorias nem na transcrição dos questionários para não estendermos demasiadamente

\footnotetext{
${ }^{8}$ Em alguns momentos do texto haverá a passagem da terceira pessoa para a primeira pessoa de forma abrupta. Essa escolha tem o intuito de demarcar a experiência de uma das autoras como assessora de escrita, e o singular visa também deixar claro que a assessoria é um momento privado entre o(a) assessor(a) e o(a) assessorado(a) -, o que condiz com o texto em primeira pessoa. Em outros momentos, a reflexão é demarcada na terceira pessoa, pois ambas as autoras refletem sobre os processos de significação da escrita. Tendo em vista que o texto é um diálogo, propomos esse exercício reflexivo sobre as vozes de constituição de um texto, seus plurais e singulares, seus tempos e gêneros, que se misturam também com sua voz, leitor(a), pois é a partir dela que você lê e escuta esta conversa.
} 
o espaço de discussão. No entanto, pontuamos mais uma questão que necessita de destaque: o que é perceptível, e muito latente, no contato desses indivíduos com as assessorias é, primeiramente, um contato com suas próprias emoções acerca desse processo; é um "ouvir-se" e, ao mesmo tempo, "sentir-se" seguro para falar sobre sua escrita. Posteriormente, o(a) assessorado(a) desenvolve um sentimento de integração e reconhecimento social pela comunidade em que ele está inserido. Um exemplo de resposta ao questionário que exemplifica esse viés de integração social pode ser percebido nesta transcrição de um feedback de assessorado(a): "Trabalho maravilhoso! Transmite aos pós-graduandos a sensação de fazer parte de uma comunidade, com os mesmos anseios e desejos. $\mathrm{O}$ apoio da equipe em nos conduzir e orientar com dicas faz toda a diferença. Parabéns a todos os envolvidos."

Assim, diferentemente do(a) professor(a) ou do(a) amigo(a) pessoal, que estaria fazendo um "favor" ao ajudar esse indivíduo em sua escrita, o CAPA cria um sentimento de reconhecimento social, pois é um espaço institucional capaz de atuar transformando o imaginário do(a) aluno(a). A própria Universidade, ao oferecer esse tipo de auxílio ao assessorado(a), legitima a dificuldade com a escrita acadêmica como um problema social do contexto acadêmico, e não individual. Desse modo, a significação da escrita transita de uma relação "dogmática" e "reguladora" para uma de diálogo e aprendizado constante, compartilhada e construída socialmente e não mais efetivada de maneira solitária.

Essa nova dinâmica de relação com a escrita é baseada, sobretudo, em práticas de colaboração. Tendo em vista que as relações nas universidades são, em suma, de disputa, essa mudança no imaginário do indivíduo em relação à instituição e a esse Outro que coabita com ele nesse mesmo espaço tem efeitos em seu processo de escrita. A mudança central está no fato de o

\footnotetext{
${ }^{9}$ Resposta coletada em um questionário aplicado. Uma pesquisa cuidadosa e mais elaborada está sendo desenvolvida com base nas respostas dos questionários. Para este artigo, optamos por uma descrição do panorama geral de atuação do CAPA, a fim de direcionar a discussão para as relações entre trabalho intelectual, emoções e escrita. Entretanto, se faz necessário pontuar que, assim como a escrita, a pesquisa de campo é um processo, não é um evento concluído, por mais que ela possa ser apresentada como algo acabado, ela está em constante construção e permeia múltiplas influências - principalmente a própria escrita de si, da interpretação e da pesquisadora. É importante considerar que os dados das próprias emoções relatadas pelos participantes das assessorias são também construções evidenciadas tanto por suas expressões escritas (alívio, confiança, segurança) quanto pelas expressões corporais que dão vazão as suas emoções (o riso, a descontração, as lágrimas).
} 
indivíduo poder falar sobre suas emoções, tanto em relação à escrita quanto ao campo acadêmico. Isso é similar à perspectiva apontada por Bourdieu (2001, p. 18), que afirma que "Nada é mais universal e universalizável do que as dificuldades. Cada um achará uma certa consolação no facto de descobrir que grande número das dificuldades imputadas em especial à sua falta de habilidade ou à sua incompetência são universalmente partilhadas".

Assim, com base na contextualização do CAPA apresentada, identificamos uma potente reflexão: de que modo o controle das emoções na escrita acadêmica interfere na construção do conhecimento e na relação que o pesquisador estabelece com o trabalho intelectual e com a instituição?

O que se pode considerar é que, mesmo que a universidade se caracterize como um espaço privilegiado de compreensão do mundo, a reflexão sobre a constituição e o funcionamento de seu próprio meio não são refletidos nem debatidos com o mesmo grau de intensidade e esforço. Howard Becker (2015), ao refletir sobre a organização social da escrita, aponta esse efeito paradoxal nas ciências sociais: o sociólogo, que teria por função desvendar os fenômenos sociais considerados como "naturais", o faz com base em sua prática acadêmica envolta pela escrita, que, por sua vez, também é um fenômeno social. No intuito de desnaturalizar os fenômenos fora do contexto social acadêmico, ele deixa de desnaturalizar seu próprio contexto. Percebemos, então, que no campo da sociologia, tal como afirma Bernard Lahire (2001, p. 151), "as práticas de escrita aparecem assim, ao entendimento acadêmico, como um objeto «bizarro», «insignificante» e sem importância face aos «grandes problemas» ou aos «grandes temas» instituídos". Para Lahire (2001, p. 151), a consequência disso é o aumento das preguiças interpretativas, que dificultam o avanço do conhecimento sociológico.

Essa mesma perspectiva da escrita pode ser revisitada também na Antropologia, desde a década de 1980, principalmente em autores clássicos como Clifford Geertz, Paul Rabinow, James Clifford, entre tantos outros. James Clifford, em especial, aponta que escrita "não é mais uma dimensão marginal ou oculta, mas vem surgindo como central para aquilo que os antropólogos fazem, tanto no campo quanto no que a ele se segue." (CLIFFORD, 2016, p.32). E, assim como observado por Becker e Lahire, Clifford também destaca "o fato de que até recentemente a escrita não tenha sido retratada ou seriamente discutida reflete a persistência de uma ideologia que reivindica a transparência da representação e o imediatismo da experiência." (CLIFFORD, 2016, p.32). 
Nesse sentido, Paulo Ricardo Müller (in MÜLLER, CLIFFORD, MARCUS, 2019), em sua resenha da obra - A escrita da cultura: poética e política da etnografia - traz uma reflexão importante para as questões acerca da escrita acadêmica que buscamos discutir neste artigo. Ele aponta:

Ironicamente, a reflexão sobre a escrita etnográfica parece
ter influenciado novas gerações de antropólogos a prestarem
maior atenção às dinâmicas de inserção em campo, mais do
que a adotarem estilos ou estratégias literárias distintas da
escrita acadêmica tradicional. Ou seja, passou-se a analisar mais
criticamente não aquilo que os textos antropológicos clássicos
revelam, mas aquilo que ocultam sob o manto da objetividade
científica: as negociações da posição do etnógrafo na sociedade
pesquisada e suas condições intersubjetivas de observação e
interação. (MULLER; CLIFFORD, MARCUS, 2019, p. 303)

Outra perspectiva potente refletida por Clifford é de que "os gêneros acadêmicos e literários se interpenetram e que a escrita de descrições culturais é propriamente experimental e ética." (CLIFFORD, 2016, p.32), e mais que isso: os relatos culturais têm uma natureza artificial e construída. Entretanto, mesmo que a desconstrução dessas dicotomias entre arte/ ciência, razão/emoção, corpo/mente tenha avançado no campo teórico, as práticas e os imaginários dos indivíduos sobre a escrita acadêmica ainda se encontram demarcados por essas separações. Assim, buscamos refletir na próxima seção sobre alguns desses imaginários acerca da escrita acadêmica que propiciam a manutenção de tais dicotomias.

\section{Algumas possibilidades de análise do imaginário na escrita acadêmica}

O pintor traz seu corpo para olhar o que não é ele, o músico traz seu corpo para ouvir o que ainda não tem som, o escritor traz a volubilidade de seu espírito para cercar aquilo que se diz sem ele.

(Marilena Chaú. Experiência do pensamento)

Iniciamos este momento do artigo com tal epígrafe não por acaso. Essa epígrafe, em suma, evidencia um imaginário acerca da escrita que difere do imaginário que permeia outros meios de expressão dito artísticos, em que o corpo é mais "presente" (como se fosse possível medir a presença 
do corpo). Mesmo que o movimento da autora seja em prol de uma aproximação entre a pintura, a música e o texto, o corpo no ato da escrita é apagado. Na pintura e na música, o corpo participa; já na escrita este é substituído pela volubilidade do espírito. Essa epígrafe ilustra não apenas o imaginário dessa autora, mas um imaginário coletivo recorrente no campo acadêmico, que é fruto do controle das emoções na ciência e que cria a ideia de que no campo intelectual há menos "corporalidades", logo, menos expressividade. Ao tratar da presença das emoções na escrita acadêmica, estamos assumindo a presença do próprio corpo, pois não é possível operar com a dicotomia corpo/mente, razão/emoção, arte/ciência. Escolhendo essa possibilidade de relação, a intenção não é defender a prática acadêmica como uma prática artística nem enveredar no emaranhado de significações e conceitos que definem o que pode ou não ser arte. O intuito é analisar os efeitos desse imaginário no processo de escrita acadêmica, compreendendo como este atua na regulação das emoções nesse campo.

Pensando especificamente na sociologia, é perceptível que ela avança na desnaturalização da "aura" do artista no campo da arte, ${ }^{10}$ mas, quando o foco é a escrita acadêmica, a "aura" ainda permanece com o cientista. Segundo Bruno Latour (2014), nas universidades a escrita acadêmica é passada de uma geração a outra pela operação do Espírito Santo ${ }^{11}$. É perceptível, portanto, que essa configuração é um problema de ordem social, que sedimenta um imaginário coletivo acerca da escrita acadêmica, causando efeitos sobre a constituição dos distintos saberes e também nas relações dos indivíduos tanto com a escrita quanto com os outros e com o próprio campo social.

Lahire, ao investigar as práticas "ordinárias" da escrita, como lista de mercados, bilhetes e anotações em agendas, fornece um importante referencial para essa reflexão ${ }^{12}$. $\mathrm{O}$ autor também apresenta uma grande contribuição ao refletir sobre a condição social do escritor literário, publicada em Trajetória acadêmica e pensamento sociológico: entrevista com Bernard Lahire (2004, p. 321):

\footnotetext{
${ }^{10}$ Isso é perceptível na obra A distinção: crítica social do julgamento (2007), de Pierre Bourdieu. O conceito de illusion de Bourdieu também pode ser utilizado, pois a "aura" sustenta o campo, surte sua permanência em alguma coisa.

${ }^{11}$ Usando ironia, Latour evidencia um sentido quase que dogmático sobre os imaginários e práticas da escrita acadêmica no campo científico.

${ }^{12}$ Principalmente na obra O homem plural: as molas da ação (2001).
} 
Materializar os autores da literatura é reinscrevê-los nas condições de existência social e econômica (do que eles vivem?), nas redes de interdependências literárias, paraliterárias e extraliterárias (com quem vivem e de quem dependem?) e nas condições materiais e temporais do trabalho da escrita (quando e como escrevem?). Um processo como esse se situa no cruzamento de uma sociologia das profissões (e a questão que nesse caso é particularmente instigante é a de saber em que medida a literatura pode ser encarada como uma "profissão", um "trabalho"), de uma sociologia dos processos de reconhecimento simbólico e de uma sociologia das práticas artísticas.

As questões apontadas por Lahire (2004) contribuem para a localização do objeto escrita acadêmica e a necessidade de se pensar as possíveis vias de análise que a sociologia fomenta para ela. Identificamos entre essas vias relações mais diretas, como as sociologias do conhecimento (pois a escrita é produção do conhecimento), do trabalho (pois a produção do conhecimento é um trabalho), da arte (porque a escrita é uma prática expressiva permeada pela criatividade), da educação (porque os agentes são alunos, estudantes, pesquisadores), do corpo (pois são corpos que escrevem corpos de texto) e das emoções (pois a escrita acadêmica é uma prática ligada ao controle e à exibição das emoções na expressão). Essas possibilidades demonstram um extenso referencial teórico que pode ter embasamento nesses distintos campos de análise. Contudo, o foco escolhido aqui é o de uma relação entre a sociologia das emoções, do corpo e da arte, pois acreditamos que elas também são capazes de interligar, de certo modo, os outros campos citados anteriormente.

Na busca então desse entrelugar (sociologia da arte, do corpo e das emoções), é necessário destacar alguns autores que fornecem importantes embasamentos teóricos. No que concerne à sociologia das emoções, destacamos, sobretudo, Barbelet (1998) e Kemper (2006), mencionados na análise das assessorias anteriormente. Outros autores, mesmo que não citados neste trabalho - devido ao espaço conciso de um artigo - como Norbert Elias, Erving Goffman, David Le Breton, Marina Ariza, Arlie Russel Hochschild, Eva Illouz, Axel Honnet e Loic Wacquant, também apresentam aspectos importantes referentes tanto às emoções quanto ao controle dos corpos - quais corpos podem ou não ser emotivos e em quais espaços e práticas há essa permissão. Outra autora que contribui com tal perspectiva é Sara Ahmed, que em sua obra The Cultural Politics of Emotion (2004) discute 
a hierarquia entre as emoções e a construção de um imaginário das emoções produtivas e das repreendidas (estas vistas como fraquezas). Mesmo não recebendo o devido foco, tais autores contribuíram e enriqueceram a reflexão do tema da escrita acadêmica, a pesquisa de campo e o próprio processo de escrita deste trabalho.

O mesmo podemos dizer de autores como Michel Foucault, Roland Barthes, Jacques Derrida, Félix Guattari, Gilles Deleuze, Yukio Mishima, Nathalie Gassel, bell hooks e Suely Rolnik, que embasam a relação do autor com a escrita, possibilitando o entendimento dessa prática distanciada do imaginário dicotômico corpo/literatura, emoção/ciência, escrita/política. A escrita como cuidado de si, estética de existência, é refletida por meio desses autores, a fim de se pensar os limites e as intersecções com o campo acadêmico.

No que se refere à prática da escrita acadêmica como objeto sociológico, o autor expoente, dada a relação direta com o tema, é o sociólogo Howard Becker $^{13}$, em que aqui neste artigo investimos um foco maior, e que juntamente com Bourdieu também nos fornece perspectivas da sociologia da arte. Na obra de Becker, Truques da escrita: para começar e terminar teses, livros e artigos (2015) $)^{14}$, ele discorre sobre a organização social da escrita, baseado em suas experiências em docência de escrita acadêmica para estudantes de ciências sociais nos Estados Unidos. De modo geral, o autor evidencia que os problemas que escritores acadêmicos enfrentam com a escrita não são derivados estritamente de alguma deficiência pessoal, mas sim da organização social na qual estão inseridos, pois essa organização cria tais dificuldades. Além de fornecer um considerável material sociológico, Becker (2015, p. 78-79) traz um importante "desnudamento" do uso de metáforas na escrita acadêmica:

Estou folheando os números atuais de algumas revistas de sociologia (não creio que os resultados seriam diferentes se as revistas fossem de história, psicologia ou literatura inglesa). Em quase todas as páginas, encontro metáforas batidas. "Parece faltar um argumento cortante, ferino" a um livro resenhado. [...]

\footnotetext{
${ }^{13}$ Pretendo também utilizar a perspectiva de Charles Wright Mills, que foi a principal referência de Becker no que se refere a uma sociologia da escrita. Alguns outros autores, segundo o pesquisador Robson Cruz (2018, p. 2), “também deram centralidade ao papel da produção textual na pesquisa sociológica, como Everett Hughes, Herbert Blumer, Robert Redfield, Ervin Goffman".

${ }^{14}$ Lançada no Brasil em 2015, mas publicada em 1986 nos Estados Unidos sob o título original Writing for Social Scientists: How to Start and Finish Your Thesis, Book, or Article.
} 
Quando dizemos que um argumento é "cortante" ou "ferino", a que instrumento estamos comparando e que material ele estaria supostamente cortando? [...] A literatura está sendo comparada a um corpo humano? Significa que temos de procurar seu coração, seu fígado, seu estômago, seu cérebro? [...] Usar uma metáfora é um exercício teórico sério, em que você afirma que dois fenômenos empíricos diferentes pertencem à mesma classe geral, e classes gerais sempre implicam uma teoria. Mas as metáforas só funcionam dessa maneira se tiverem frescor suficiente para atrair a atenção. Se já foram usadas e repetidas a ponto de se tornarem clichês, você não vê nada de novo.

O uso de metáforas, sobre o qual Becker (2015) reflete, é o ponto de ligação com a sociologia da arte que buscarmos construir. Essas associações se referem a analogias entre cientistas e artistas, pinturas e textos acadêmicos, campo da arte e campo acadêmico, cinema e escrita, entre outras. Essas analogias não somente evidenciam um imaginário de pertencimento da escrita acadêmica e da arte à mesma classe geral, mas também demonstram, sobretudo, um paradoxo: cria-se a ideia de que a emoção é negativa para o fazer científico, mas as figuras de linguagem e as metáforas utilizadas para descrevê-lo são justamente a arte - a prática que se difere da ciência por conta da presença da emoção.

Antes de exemplificamos essas metáforas com algumas passagens de autores da sociologia, precisamos refletir brevemente sobre essa "negatividade" das emoções. Esse aspecto foi bem retratado por Becker (2015) ao trazer uma análise de Lakoff e Johnson (1980) em seu livro. Esses dois autores refletem sobre como o corpo é causador de metáforas orientacionais, como no caso de Happy is up. Conforme explicam os autores, "O fato de que o conceito de 'feliz', happy, seja orientado para o alto, 'up', leva a expressões em inglês como 'I' $m$ feeling up today'" (LAKOFF; JOHNSON, 1980, p. 14). Seguindo nessa linha de raciocínio, os autores demonstram a lógica que se instaura: o consciente como up e o inconsciente como down. Como a ideia de consciente está ligada à razão, logo o racional é up. A ideia de inconsciente, por sua vez, está ligada à emoção, logo o emocional é down. Lakoff e Johnson exemplificam essas relações opositivas:

[...] a discussão caiu para o nível emocional, mas eu a iniciei novamente para o plano racional. Pusemos nossos sentimentos de lado e tivemos uma discussão intelectual de alto nível sobre o assunto. Ele não conseguiu se elevar acima de suas emoções. Base 
física e cultural: em nossa cultura, as pessoas se veem no controle sobre animais, plantas e seu ambiente físico, e é sua faculdade racional exclusiva que coloca os seres humanos acima dos outros animais e lhes dá esse controle. Assim, “Controle é up" pois serve de base para "Homem é up" e, portanto, para "Racional é up". (LAKOFF; JOHNSON, 1980, p. 17)

É possível, então, pensar que a busca da ciência por uma racionalidade interfere não apenas no comportamento do cientista, mas também se apropria da escrita, modelando e impondo uma estética "racional". Entretanto, mesmo que essa estética busque por uma diferenciação formal da arte, negativando as emoções, as descrições mais recorrentes do processo de escrita são associações, metáforas e analogias relacionadas à arte. Tal fato pode ser exemplificado por meio de uma passagem do próprio Becker (2015, p. 124): “Um estudioso pode tentar trabalhar isolado e sem o auxílio dos outros, como os chamados artistas primitivos, que fazem pinturas e construções sem recorrer a nenhuma tradição do meio em que trabalham".

Outro exemplo desse mesmo autor é a associação que ele utiliza para descrever o comportamento dos estudantes de pós-graduação com a escrita acadêmica: "Os estudantes têm as atitudes de muitos públicos de arte em relação aos modos 'comuns' de expressão" (BECKER, 2015, p. 44). Bourdieu (2001, p. 19) também contribui para essa associação: “O homo academicus gosta do acabado. Como os pintores acadêmicos, ele faz desaparecer dos seus trabalhos os vestígios da pincelada, os toques e os retoques [...]". Essa metáfora de Bourdieu ilustra uma relação entre escrita acadêmica e pintura e também uma ideia romântica da escrita e um imaginário de classe. $\mathrm{O}$ pesquisador Robson Cruz (2017) exemplifica bem essa associação quando reflete que, historicamente, se consolidou um ideal romântico sobre o processo de escrita que valoriza o "espontâneo" em detrimento do trabalho duro, difícil e artesanal, que é culturalmente associado a classes sociais mais baixas. Essa ideia do artesanal remete à presença do corpo no processo de construção, mas de modo distinto da arte. Ao que parece, instaura-se uma "quantidade" de corpo e mente nessas práticas: o artesanato (muito corpo, mas "menos" intelecto em relação à arte) e a arte (muito corpo, porém mais intelecto em relação ao artesanato). Quando comparadas essas duas práticas com a escrita acadêmica, o imaginário coletivo é de que a escrita acadêmica tem menos corpo e mais intelecto que a arte e o artesanato. Isso também pode apontar para uma possível via de problematização dos imaginários coletivos de diferenciação entre trabalho material versus 
trabalho imaterial, trabalho individual versus trabalho coletivo, o que possibilitaria a desnaturalização do estatuto do trabalho intelectual.

Desse modo, tais imaginários atuam diretamente nas interações sociais dentro da universidade, interferindo na relação dos sujeitos com a escrita, com os outros e com o campo. Assim, os conceitos de Bourdieu de habitus e de campos possibilitam refletir as práticas de escrita acadêmica e do campo ao qual ela se insere, esclarecendo o processo que se instaura de sua conversão em capital simbólico dentro da universidade. As obras principais que fornecem tal reflexão são O poder simbólico (2001), Economia das trocas linguísticas (2008), Esboço de autoanálise (2005), Homo Academicus (2008) e Distinção: crítica social do julgamento (2007). Esta, em especial, avança no problema que identificamos presente: a relação entre conteúdo e forma. A análise que Bourdieu executa sobre a disposição estética para a arte é passível de ser relacionada à disposição estética para a escrita, o que desmistifica, assim, a construção "natural" do escritor acadêmico, que é disseminada nas universidades.

Essas associações paradoxais que prezam controle das emoções na escrita, mas associam a escrita à arte, são recorrentes não apenas no campo da sociologia, mas também nas outras áreas do saber e até mesmo em manuais de escrita e metodologia, livros sobre produção de artigos e textos sobre gênero acadêmico. Um exemplo que ilustra bem essa associação é a obra Produção textual na universidade (2010), de Désirée Motta-Roth e Gabriela Rabuske Hendges. Em pesquisas realizadas com base na teoria sociorretórica de John Swales, as autoras abordam gêneros centrais do contexto acadêmico, como resenha, projeto de pesquisa, artigo científico e abstract. O que se destaca na obra é a associação, por meio de imagens, entre a escrita acadêmica e as obras artísticas. Cada capítulo se inicia com a imagem de uma obra; entretanto, o porquê da presença dessas imagens em cada capítulo não é explicado pelas autoras.

Dessa forma, é importante trabalhar juntamente com as teorias sociológicas as metáforas que os autores utilizam para pensar suas práticas. Mesmo que o autor não se proponha a investigar diretamente a relação entre a arte e a escrita acadêmica, ele faz essa associação quando utiliza a arte para descrever seu meio e suas práticas. Além dos autores já mencionados, vale citar também alguns outros que, inclusive, produzem suas teorias baseados nessa relação. É o caso de Lahire, em O homem plural (2001), em que os capítulos são caracterizados como "cenas", e o autor defende que "o escrito permite selecionar, como no cinema, as melhores sequências (...)" 
(LAHIRE, 2001, p. 171), e de Charles Wright Mills, em Sobre o artesanato intelectual e outros ensaios (2009). Nessa obra, Mills faz referência à escrita não somente como meio de produção do trabalho intelectual, mas como um processo de reflexão que "corporifica os momentos, horas e dias mais alertas que jamais tivemos" (MILLS, 2009, p. 95). Essa retomada ao corpo é percebida também em Haruki Murakami, ao relacionar a escrita com a corrida, e em Yukio Mishima e Nathalie Gassel, quando associam a escrita ao fisiculturismo.

Com base na reflexão de Boaventura de Souza Santos (1989), que afirma que é urgente e necessária uma nova forma de fazer ciência, é possível pensar e propor novas formas de escrever e se inscrever no texto acadêmico. Santos (1989) aponta a necessidade de uma ciência que tenha consciência e faça uma revisão estrutural da construção epistemológica, ou seja, de como se produz o conhecimento. E seria fundamental para o cientista-pesquisador ter uma atitude hermenêutica, deixando claro que a ciência é uma "prática social de conhecimento, uma tarefa que se vai cumprindo em diálogo com o mundo e que é, afinal, fundada nas vicissitudes, nas opressões e nas lutas que o compõem" (SANTOS, 1989, p. 13).

\section{Considerações finais}

Caminhando para uma tentativa de finalização, refletimos com a ideia de que, apesar de as teses, as dissertações e os artigos serem também meios de expressões, estes não são assumidos nem compreendidos como tal no campo acadêmico. O imaginário coletivo dicotômico entre arte/ciência, corpo/ mente, emoção/razão ainda é fortemente empregado no processo criativo da escrita acadêmica. Essas dicotomias também intensificam a distinção entre trabalho material/imaterial, produção individual/coletiva e trabalho braçal/mental. Mesmo que o trabalho intelectual ainda seja caracterizado por sua imaterialidade, ele se corporifica na escrita. A escrita, por sua vez, é construção coletiva, é também emoção, expressão, é corpo. E não é exatamente o corpo, o "fazer braçal", que possibilita a sua materialidade?

Buscamos neste artigo refletir sobre como o controle das emoções na escrita acadêmica interfere na construção do conhecimento e na relação que o pesquisador estabelece com o trabalho intelectual, fazendo com que a escrita acadêmica seja, por muitas vezes, uma experiência traumática e incompreendida por quem a pratica. A associação de tal problema ao psicológico e ao individual do sujeito ameniza a responsabilidade do 
coletivo e promove ainda mais a manutenção dessa situação. As assessorias oferecidas pelo CAPA, portanto, podem se configurar como uma alternativa para lidar com esse problema, pois possibilitam desenvolver uma compreensão sobre o processo do trabalho intelectual, identificando o corpo/emoção como materiais compositivos, e alterar, assim, as relações tanto com a escrita quanto com o campo acadêmico.

Neste momento de finalização de um diálogo textual, propomos uma abertura. Já que ao longo do artigo intentamos demonstrar os imaginários dicotômicos entre arte e ciência, emoção e razão, agora convidamos Malinowski para contribuir com uma de suas potentes reflexões, pois acreditamos que há uma grande recompensa na investigação das emoções no trabalho intelectual, que está muito além de uma teoria: ela se relaciona a essa presença inegável de tantos corpos/emoções que escrevem outros tantos corpos de textos/expressões.

Estudar as instituições, costumes e códigos, ou estudar o comportamento e mentalidade do homem, sem atingir os desejos e sentimentos subjetivos pelos quais ele vive, e sem o intuito de compreender o que é, para ele, a essência de sua felicidade, é, em minha opinião, perder a maior recompensa que se possa esperar do estudo do homem. (MALINOWSKI, 1978, p. 33-34)

\section{Referências}

AHMED, Sara.

(2004). The Cultural Politics of Emotion. New York: Routledge.

ARIZA, Marina.

(2016). La sociologia de las emociones como plataforma para la investigación social. In: Emociones, afectos y sociologia Diálogos desde la investigación social y la interdisciplinar. México: UNAM.

ARENDT, Ronald João Jacques.

(2016). A escrita como laboratório. Rev. Polis Psique [online], v. 6, n. spe, pp. 28-38.

BAKHTIN, Mikhail.

(2003). Estética da criação verbal. São Paulo: Martins Fontes.

BARBALET, Jack. M.

(1998). Emoção, teoria social e estrutura social. Lisboa: Instituto Piaget.
BARTHES, Roland.

(2008). O prazer do texto. Tradução de J. Guinsburg. São Paulo: Perspectiva.

(1998). 0 rumor da língua. Tradução de Mário Laranjeira. São Paulo: Brasiliense.

BECKER, Howard.

(2207). Segredos e truques de pesquisa. Tradução Maria Luiza X. de Borges. Rio de Janeiro: Zahar.

(2015). Truques da escrita: para começar e terminar teses, livros e artigos. Rio de Janeiro: Zahar.

BOURDIEU, Pierre.

(2008a). Homo academicus. Tr. Ariel Dilon. Buenos Aires, Edit. Siglo XXI. 
(2008b). A economia das trocas linguísticas. São Paulo: Edusp.

BOURDIEU, Pierre.

(2007). A distinção: crítica social do julgamento. São Paulo: Edusp; Porto Alegre: Zouk.

(2005). Esboço de autoanálise. São Paulo: Companhia das Letras.

(2001). 0 poder simbólico. Tradução de Fernando Tomaz. Rio de Janeiro: Bertrand Brasil.

(1983a). Esboço de uma teoria da prática. In: ORTIZ, Renato (Org.). Pierre Bourdieu: sociologia. Trad. de Paula Montero e Alícia Auzmendi. São Paulo: Ática. pp. 46-81.

(1983b). 0 campo científico. In: ORTIZ, Renato (Org.). Pierre Bourdieu: sociologia. Tradução de Paula Montero e Alícia Auzmendi. São Paulo: Ática.

\section{CAPA}

(2019). Centro de Assessoria de Publicação Acadêmica. 0 que é o CAPA? Disponível em: <http://www.capa.ufpr.br/portal/about/>. Acesso em: 26 nov. 2018.

CHAUI, Marilena.

(2002). Experiência do pensamento: ensaios sobre a obra de Merleau-Ponty. São Paulo: Martins Fontes.

CLIFFORD, James; MARCUS, George.

(2016). A escrita da cultura: poética e política da etnografia. Tradução de Maria Claudia Coelho. Rio de Janeiro: Papéis Selvagens, EdUFRJ.

CRUZ, Robson Nascimento.

(2018). Becker e o silêncio sobre a escrita na pós-graduação: soluções antigas para o cenário brasileiro atual? Psicol. Soc., Belo Horizonte, v. 30, e167038. (2017a). Palestra. Saúde mental e o bloqueio da escrita na pós-graduação. YouTube, 27 out. Disponivel em: <https://www.youtube.com/ watch? $v=S \_Z q L e k L 3 t Y>$. Acesso em: 31 maio 2018. Parte 1.

(2017b). Palestra. Saúde mental e o bloqueio da escrita na pós-graduação. YouTube, 27 out. Disponivel em: <https://www.youtube.com/ watch?v=i59IZAW-r90>. Acesso em: 31 maio 2018. Parte 2.

DURKHEIM, Émile.

(2004). Sociologia e filosofia. Tradução de Fernando Dias Andrade. São Paulo: Ícone.

(1976). As regras do método sociológico. São Paulo: Companhia Editora Nacional.

ELIAS, Norbert.

(2012). Quadros da experiência social. Petrópolis: Vozes.

(2001). A sociedade de corte. Rio de Janeiro: Jorge Zahar.

(1998). Sobre los seres humanos y sus emociones: "un ensaio sociológico processual": la civilización de los padres y otros ensaios. Colombia: Grupo Editorial Norma.

(1993). O processo civilizador. v.2. Rio de Janeiro: Zahar.

GOFFMAN, Erving.

(1985). A representação do eu na vida cotidiana. Petrópolis: Vozes.

(1978). Estigma: notas sobre a manipulação da identidade deteriorada. Rio de Janeiro: Zahar Editores.

FAIRCHILD, Thomas.

(2017). Da interpretação à apreciação: a autoria acadêmica no novo contexto do novo 
produtivismo. Revista Trama, v. 13, n. 28, pp. 2013-239.

FOUCAULT, Michel.

(1992). 0 que é um autor? Tradução de Antônio Fernando Cascais e Eduardo Cordeiro. Lisboa: Vega.

GASSEL, Nathalie.

(2005). Construction d'un corps pornographique:

Ah! Bruxelas: Editions Cercle d'Art.

GIDDENS, Anthony.

(1998). Política, sociologia e teoria social. São Paulo: UNESP.

GUATTARI, Félix; ROLNIK, Suely.

(2005). Micropolíticas: cartografias do desejo.

7. ed. Petrópolis: Vozes.

HICKS, Diana et al.

(2015). The Leiden Manifesto for Research Metrics. Nature, v. 520, n. 7.548, pp. 429-431.

HOCHSCHILD, Arlie Russel.

(2003). The Managed Heart: Commercialization of Human Feelings. California: University of California Press.

IANNI, Otávio.

(2004). Variações sobre arte e ciência. Tempo Social, v. 16, pp. 7-23, jun.

ILLOUZ, Eva.

(2016). Por qué duele el amor: una explicación sociológica. Trad. María Rodil. 2. ed. Buenos Aires: Katz Editores.

KEMPER, T. D.

(2006). Power and status and the power-status theory of emotions. In: Handbook of the sociology of emotions, 87-113. Boston, MA: Springer.

$\overline{(2002)}$. Predicting emotions in groups: Some lessons from September 11. The Sociological Review 50, n² 2_suppl: 53-68.

$\overline{(1990)}$. Themes and Variations in the Sociology of Emotions. In: Research agendas in the sociology of emotions, edição: Theodore D. Kemper, 3-21. Suny Press.

LAHIRE, Bernard.

(2004). Trajetória acadêmica e pensamento sociológico: entrevista com Bernard Lahire. Educação \& Pesquisa, v. 30, n. 2, pp. 315-321.

(2001). O homem plural: as molas da ação. Lisboa: Instituto Piaget.

LAKOFF, George; JOHNSON, Mark.

(1980). Metaphors We Life By. Chicago: University of Chicago Press.

LATOUR, Bruno.

(2014). L'influence est un risque. Postface. In: TOLLIS, Clair. ; CRÉTON- CAZANAVE, Laurence.; AUBLET, Benoit. (Org.). L'effet Latour: ses modes d'existence dans les travaux doctoraux. Paris: Éditions Glyphe..

LATOUR, Bruno; WOOLGAR, Steve.

(1997). A vida de laboratório: a produção dos fatos científicos. Tradução de Ângela Ramalho Vianna. Rio de Janeiro: Relume Dumará.

LE BRETON, David.

(2012/2013). Por uma antropologia de las emociones. Revista Latino Americana de Estudios sobre Cuerpos, Emociones y Sociedad., v. 4, n. 10.

(2006). A sociologia do corpo. Petrópolis: Rio de Janeiro: Vozes.

(2003a). Adeus ao corpo: antropologia e sociedade. Campinas: Papirus.

(2003b). Antropologia do corpo e modernidade. Rio de Janeiro: Vozes.

MALINOWSKI, Bronislaw.

(1978). Argonautas do Pacífico Ocidental. São Paulo: Abril Cultural.

MARTINEZ, Ron; GRAF, Karin.

(2016). Thesis Supervisors as Literacy Brokers in Brazil. Publications, v. 4, n. 26, pp. 1-10. 
MILLS, Charles W.

(2009). Sobre o artesanato intelectual e outros ensaios. Rio de Janeiro: Jorge Zahar.

MISHIMA, Yukio.

(1985). Sol e aço. Tradução de Paulo Leminki. São Paulo: Brasiliense.

MOTTA-ROTH, Désirée; HENDGES, Gabriela Rabuske.

(2010). Produção textual na universidade. São Paulo: Parábola Editorial.

MULLER, Paulo. CLIFFORD, James; MARCUS, George.

(2019). A escrita da cultura: poética e política da Etnogafia. Cadernos De Campo (São Paulo 1991), 28(1), pp. 302-307.

RÉGIS, Sônia.

(1996). Literatura como ciência. Tese (Doutorado em Comunicação e Semiótica). Pontifícia Universidade Católica de São Paulo, São Paulo.
SANTOS, Boaventura de Sousa.

(1989). Introdução a uma ciência pós-moderna. Rio de Janeiro: Graal.

SUELY, Rolnik.

(2007). Cartografia sentimental: transformações contemporâneas do desejo. Porto Alegre: Sulina, UFRGS.

WACQUANT, LoÏc.

(2002). Corpo e alma: notas etnográficas de um aprendiz de boxe. Rio de Janeiro: Relume Dumará.

\section{Recebido em}

novembro de 2018

\section{Aprovado em}

novembro de 2019 